\title{
Positive Effects of Post-ischemic Forced Treadmill Training on Sensorimotor and Learning Outcomes Following Transient Global Cerebral Ischemia
}

\author{
Mehdi Seydyousefi (MSc) \\ Department of Physical Education and \\ Sport Sciences, Bojnourd Branch, \\ Islamic Azad University, Bojnourd, Ira \\ Ziya Fallahmohammadi (PhD) \\ Faculty of Sport Sciences, University \\ of Mazandaran, Mazandaran, Iran \\ Mahtab Moazzami (PhD) \\ Department of Exercise Physiology, \\ Faculty of Physical Education and \\ Sport Science, Ferdowsi University of \\ Mashhad, Mashhad, Iran \\ Ali Yaghoubi (PhD) \\ Department of Physical Education and \\ Sport Sciences, Bojnourd Branch, \\ Islamic Azad University, Bojnourd, \\ Iran \\ Zeinab Faghfoori (PhD) \\ Food Safety Research Center (Salt), \\ Semnan University of Medical \\ Sciences, Semnan, Iran \\ Corresponding author: Ziya \\ Fallahmohammadi \\ Email: zia-falm@umz.ac.ir \\ Tel: +981135302201 \\ Address: Faculty of Sport Sciences, \\ University of Mazandaran, Iran \\ Received: 25 Aug 2018 \\ Revised: 15 Sep 2018 \\ Accepted: 17 Sep 2018 \\ (c) (1) (9) \\ This work is licensed under a Creative \\ Commons Attribution 4.0 License.
}

ABSTRACT

Background and objectives: Stroke is one of the leading causes of death and long-term acquired disability. It is of great importance to seek ways for improving motor, sensory, and cognitive function after stroke and brain injury. In this regard, therapeutic exercise is the most commonly used method of rehabilitation that can significantly reduce the severity of functional damage. The aim of the present study was to investigate effects of eight weeks of forced treadmill training on cognitive and motor functions in ischemic rats.

Methods: Fourteen adult male Wistar rats were divided into an exercise group and a control group (no exercise). 0cclusion of both common carotid arteries was made to induce cerebral ischemia. Twenty-four hours after the induction of ischemia, the subjects in the exercise group were subjected to treadmill running, five days a week for eight weeks. The skilled ladder rung walking task was used to evaluate motor function before and after the stroke.

Results: The number of errors was decreasing in both groups, but significant differences were observed in the motor function between the two groups in the third, fifth, and eighth week.

Conclusion: 0ur results suggest that post-ischemic exercise might modulate ischemia-induced hippocampal injury and ameliorate the subsequent memory and motor impairment.

Keywords: Stroke, Cerebral Ischemia, Exercise, Treadmill training, sensorimotor.

This paper should be cited as: Seydyousefi M, Fallahmohammadi Z, Moazzami M, Yaghoubi A, Faghfoori Z [Positive Effects of Post-ischemic Forced Treadmill Training on Sensorimotor and Learning Outcomes Following Transient Global Cerebral Ischemial. mliaoums. 2019; 13(2):34-40 


\section{INTRODUCTION}

Stroke is a leading cause of death and long-term disability worldwide $(1,2)$. Despite the decrease in the incidence and mortality rates associated with stroke in high-income countries, the condition in low- and middleincome countries has worsened noticeably over the last four decades (3). It is estimated that about 15 million new stroke cases occur annually, five million of which lead to mortality and another five million suffer from permanent disability, thus imposing a burden on families and the community (4). Ischemic stroke accounts for $80-85 \%$ of all strokes, and is caused by a sudden obstruction of a major feeding vessel, which reduces local blood flow and oxygen and nutrients delivery to the affected brain tissue (4-6). The hippocampal CA1 region plays an essential role in learning and memory functions. The pyramidal neurons in this region are highly vulnerable to degeneration and cerebral ischemia $(7,8)$.

In an experimental study, occlusion of bilateral common carotid arteries led to progressive cognitive impairment and significant loss of cells in the hippocampal CA1 subfield (9). Ischemic stroke usually causes permanent damage to the brain tissue, which often leads to long-term decline in motor, sensory, and/or cognitive function, all of which significantly reduces the quality of life of patients $(10,11)$. There is currently no approved method of improving brain recovery after stroke. Thus, identifying potentially useful compounds or methods for recovery and improved functioning of the brain is a priority (12). Moreover, discovering neuroprotective factors for use during or after a stroke event is necessary (13).

Today, therapeutic exercise is the most common method of rehabilitation that can significantly reduce the severity of functional damage (14). Previous studies have shown the positive effects of exercise on physical recovery after stroke via improvement of muscle strength and tone, walking ability, and pulmonary functioning (15-17). These exercises usually include wheel running, voluntary and involuntary exercise, and forced treadmill running, all of which can contribute to motor function improvement (18). Treadmill exercise has been studied for many years as a strategy for promoting locomotor recovery (19-22). It is generally used in subacute stroke period, which is known as the golden time for treatment and recovery (23). However, in recent years, post-stroke treadmill exercise in the subacute phase has been thought to induce more brain damage. Treadmill exercise has been used as a compulsory exercise in animal studies, which may produce stress and negative effects on animals' recovery. The hippocampus is an important target of stress hormones that can influence structural plasticity of the hippocampus (24). However, Ahn et al. showed that long-term treadmill exercise improves memory impairment by reversing the decreased expression of synaptic cell adhesion molecule in the hippocampus of rats with transient cerebral ischemia (25). Some other researchers believe that treadmill exercise has neuroprotective effects $(26,27)$. Given the controversy regarding the effect of treadmill exercise on motor function recovery $(18,27$, 28 ), the present study aimed to investigate effects of eight weeks of forced treadmill training on cognitive and motor functions in ischemic rats.

\section{MATERIALS AND METHODS}

This study was approved by the Ethics Committee of Semnan University of Medical Sciences, Iran (code: IR.SEMNAN.REC.1397.057). Fourteen adult male Wistar rats (weighting 260-300g) were purchased from the Amol Pasteur Institute, Iran. The animals were housed in standard cages, under controlled environment (22-24 ${ }^{\circ} \mathrm{C}, 45-50 \%$ humidity, and 12:12h light/dark cycle), with free access to food and water. All experiments were performed in accordance with the Declaration of Helsinki. The subjects were randomly divided into two equally-sized study groups: an exercise group (eight weeks of post-ischemic exercise) and a control group (no exercise). Occlusion of both common carotid arteries was made in all animals. To induce transient cerebral ischemia (29), the rats were anesthetized with intraperitoneal injection of ketamine/xylazine $(40 \mathrm{mg} / \mathrm{kg})$, an both common carotid arteries were exposed and freed from the carotid sheath, then the vagus nerve was detached carefully. Both common carotid arteries were blocked for 45 min using microclips. Subsequently, the carotid arteries were freed and inspected for immediate reperfusion. By releasing the clips, 
blood flow was restored. Rectal temperature was maintained at $36.5 \pm 0.5{ }^{\circ} \mathrm{C}$ during the surgery using a feedback-regulated heating system. After the surgery, the animals were returned to their home cage and kept separately for four days.

Twenty-four hours after the induction of ischemia, subjects in the exercise group were subjected to treadmill running, five days a week for eight weeks. Before the treadmill training began, the rats were familiarized with the activity for $10-15 \mathrm{~min}$ at $15 \mathrm{~m} / \mathrm{min}$ and $0 \%$ slope for two days. Initially, electrical shocks (1.0 mA) were used to force animals to run forward. Then, they ran without electrical stimulation. In the first week, the subjects ran at speed of $18 \mathrm{~m} / \mathrm{min}\left(0^{\circ}\right.$ slope $)$ for 20 min five days a week. The duration and intensity of exercise and treadmill slope were increased gradually, so that the animals were running for $50 \mathrm{~min}$ at $30 \mathrm{~m} / \mathrm{min}\left(10^{\circ}\right.$ slope $)$ in the eighth week (30). In order to monitor any stress induced by treadmill running, body weight was monitored every three days.

The skilled ladder rung walking test was used to measure motor function in the contralesional forelimb before and after the stroke, according to a method described previously (31). At first, all 14 rats were exposed to a skilled ladder rung walking apparatus and then allowed to cross the apparatus three successive times for two days. At the beginning of each trial, the rats were placed on a platform at one end of a horizontal ladder obstacle with randomly spaced rungs. The subjects were filmed with a highdefinition video camcorder (Canon, Japan) while walking across the bars to a platform at the opposite end. Three complete trials were recorded in each test (at baseline and 24 hours, one week, three weeks, five weeks and eight weeks after the induction of stroke). In addition, the subjects mass was measured and recorded on each test day. All videos were scored based on the errors in the task in an observer-blind manner. Foot or paw placement on the rungs (Figure 1) was rated based on its position and using a 7-category scale (Table 1) (32). To quantify the lesion volume, the subjects were euthanized with an overdose of sodium pentobarbital $(100 \mathrm{mg} / \mathrm{kg})$, perfused with $0.9 \%$ saline, followed by $4 \%$ paraformaldehyde.

The brain was removed and fixed in $4 \%$ paraformaldehyde for 24 hours at $4{ }^{\circ} \mathrm{C}$, cryoprotected by $30 \%$ sucrose, and then flash frozen. The specimens were stored at $-80{ }^{\circ} \mathrm{C}$ until sectioning. The frozen brains were sectioned at $50 \mu \mathrm{m}$ on a cryostat, and then processed via cresyl violet staining as described elsewhere $(33,34)$. Figure 2 shows the results of cresyl violet staining of brain sections.

Normal distribution of data was assessed using the Kolmogorov-Smirnov test. Independentsamples t-test was used to compare differences between the groups, and within-group differences over time were analyzed using repeated measures ANOVA. All statistical analyses were performed using SPSS (SPSS Inc., Chicago, IL, USA; Version 16.0) at significance level of 0.05 .

\section{RESULTS}

As shown in figure 2, the proportion of live cells deceased from $90-90 \%$ to $35-40 \%$ after the induction stroke. However, this decrease was somewhat reversed in the exercise group after the training intervention (60-70\% live cells).

At baseline, we detected no significant difference in terms of performance and mean digit scores between the two groups $(\mathrm{P}=0.71)$. Twenty-four hours after the stroke, the number of errors significantly increased in both groups $(\mathrm{P}<0.001)$. The mean scores had a decreasing trend in both groups.

However, significant changes were observed in the fifth and eight week in the control group and in the third, fifth and eighth week in the exercise group. Following stroke, significant differences were observed between the two groups in the third, fifth and eighth week (Figure 3).

Table 1 -Rating scale for foot placement in the skilled ladder rung walking test (32)

\begin{tabular}{ccc}
\hline Category & Type of foot misplacement & Characteristics \\
\hline $\mathbf{0}$ & Total miss & Deep fall after limb missed the rung \\
1 & Deep slip & Deep fall after limb slipped off the rung \\
2 & Slight & Slight fall after limb slipped off the rung \\
3 & Replacement & Limb replaced from one rung to another \\
4 & Correction & same rung was corrected \\
5 & Partial placement & Limb aimed for one rung but was placed on another Or: Limb position on \\
6 & Correct placement & Limb placed on rung with either digits/toes or wrist/heel \\
\end{tabular}


Figure 1- The skilled ladder rung walking task test

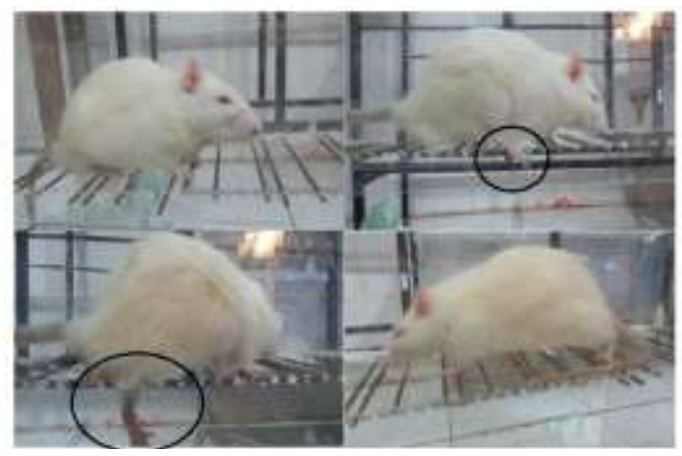

Figure 2- The results of cresyl violet staining of frozen brain sections. A: Before induction of stroke (90-95\% live cells), B: after induction of stroke (35-40\% live cells) and C: after the exercise training (60-70\% live cells).

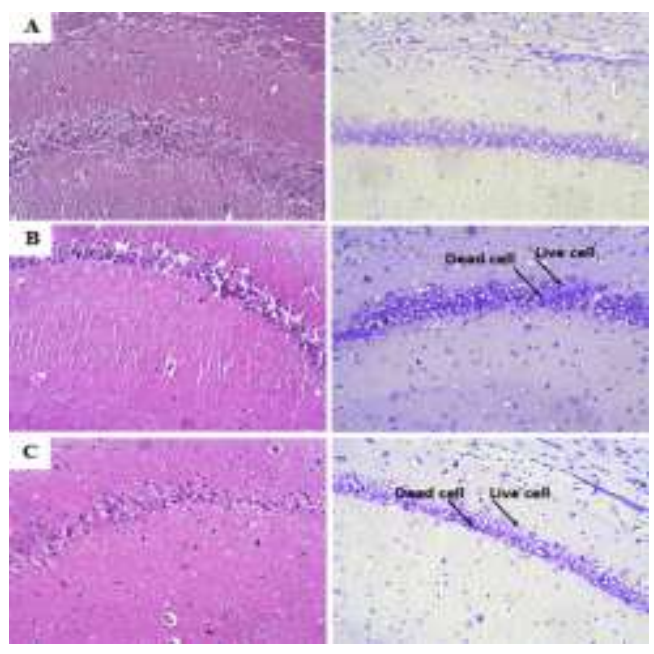

Figure 3 -Mean digit scores in the experimental groups. Asterisks indicate significant differences between the two animal groups $(\mathbf{P}<0.05)$

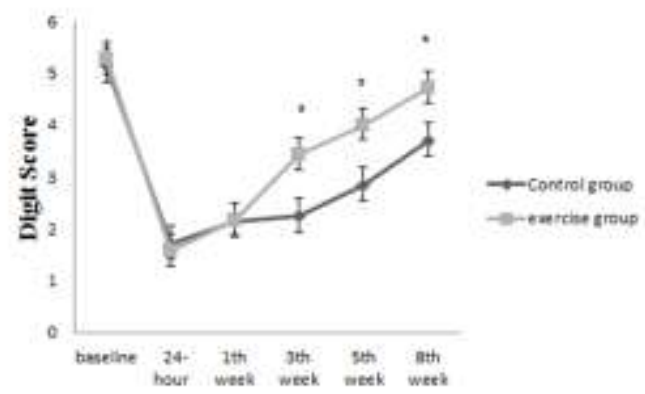

\section{DISCUSSION}

Bilateral common carotid artery occlusion is one of the easiest and the most reliable methods of inducing stroke in animal models. Temporary blockage of carotid arteries could cause neuronal cell death in the hippocampal CA1 region and therefore result in a decline in spatial learning and memory $(35,36)$. In the present study, occlusion of common carotid artery for 45 minutes caused a significant damage to the hippocampus. To induce transient cerebral ischemia, Aboutaleb et al. (37) and Erfani et al. (29) both performed occlusion of the common carotid arteries for 20 minutes. The functional disabilities caused by stroke are usually retained for years or even decades, resulting in a lifelong decline in quality of life $(34,36)$. It has been proposed that physical exercise may improve neurological impairment by impeding neuronal loss following brain injury (38). The results of the present study indicated that treadmill training might accelerate the recovery of sensorimotor, behavioral, and learning function in rats after bilateral common carotid 
artery occlusion and induction of stroke. Performing endurance exercise (run and/or reach training) five days after the induction of stroke increased recovery of skilled reaching ability but did not modulate gross motor skills, such as postural support (forelimb asymmetry test) and gait (ladder rung walking test) (39). In another study, pre-ischemic running on treadmill for four weeks, five days a week significantly reduced brain edema and neurological movement disorders caused by brain ischemia and reperfusion in male rats (40).

Pre-stroke exercise in form of treadmill running (30 $\mathrm{min}$ a day for three weeks) decreased neurologic deficits and infarct volume in the frontoparietal cortex and dorsolateral striatum (41). Lovatel and coworkers investigated effects of pre- and post-ischemic exercise on hippocampal glial cells following global cerebral ischemia in Wistar rats. They reported that the postischemic exercise modified astrocyte and microglia immunostaining in the hippocampus and partially reversed the ischemia-induced increase on the area occupied by microglia (42). The precise mechanisms through which physical exercise can exert neuroprotective effects are not understood (38). It is demonstrated that insulin-like growth factor-I may be involved in the protective effect of exercise against hippocampal injury and the subsequent memory impairment. This potent neurotrophic hormone has been shown to Conflict of interest. regulate neuronal survival, differentiation, and synaptic plasticity in the rat hippocampus (43). Sim et al.

\section{REFERENCES}

1. Feigin VL, Forouzanfar MH, Krishnamurthi R, Mensah GA, Connor M, Bennett DA, et al. Global and regional burden of stroke during 1990-2010: findings from the Global Burden of Disease Study 2010. Lancet. 2014; 383(9913): 245-54.

2. Rogers JM, Foord R, Stolwyk RJ, Wong D, Wilson PH. General and Domain-Specific Effectiveness of Cognitive Remediation after Stroke: Systematic Literature Review and Meta-Analysis. Neuropsychol Rev. 2018. doi: 10.1007/s11065-018-9378-4.

3. Norrving B, Kissela B. The global burden of stroke and need for a continuum of care. Neurology. 2013; 80(3 Suppl 2): S5-12. doi: 10.1212/WNL.0b013e3182762397. demonstrated that long-term treadmill exercise (30 min a day for four consecutive weeks) in gerbils overcomes theischemia-induced apoptotic neuronal cell death and thus helps recovery of short-term memory impairment induced by brain ischemia (38).

It seems that the neuroprotective effects of exercise, at least in part, are mediated through the upregulation of neurotrophin factors such as nerve growth factor and brain-derived neurotrophic factor, which can induce neural regeneration (44).

\section{CONCLUSION}

It seems that physical exercise may be a beneficial approach for the prevention or enhanced recovery of lifelong disabilities caused by stroke. Our results suggest that postischemic exercise might modulate ischemiainduced hippocampal injury and ameliorate the subsequent memory and motor impairment. However, more studies should be conducted in this regard in order to determine the appropriate type, duration, and intensity of exercise.

\section{ACKNOWLEDGEMENTS}

This research project received financial support from the Semnan University of Medical Sciences, Iran (code: A-10-377-2). The authors would like to thank the Biomedical and Experimental Sports Research Center of Shahid Mirghani and all those who have contributed to this study.

\section{CONFLICT OF INTEREST}

The authors declare that there is no

4. Namale G, Kamacooko O, Kinengyere A, Yperzeele L, Cras P, Ddumba E, et al. Risk Factors for Hemorrhagic and Ischemic Stroke in Sub-Saharan Africa. J Trop Med. 2018; 2018: 4650851. doi: 10.1155/2018/4650851.

5. Bennett DA, Krishnamurthi RV, Barker-Collo S, Forouzanfar $\mathrm{MH}$, Naghavi $\mathrm{M}$, Connor $\mathrm{M}$, et al. The global burden of ischemic stroke: findings of the GBD 2010 study. Glob Heart. 2014; 9(1): 107-12. doi: 10.1016/j.gheart.2014.01.001

6. Musuka TD, Wilton SB, Traboulsi M, Hill MD. Diagnosis and management of acute ischemic stroke: speed is critical. Cmaj. 2015; 187(12): 887-93. doi: 10.1503/cmaj.140355. 
7. Quintana P, Soto D, Poirot O, Zonouzi M, Kellenberger S, Muller D, et al. Acid-sensing ion channel la drives AMPA receptor plasticity following ischaemia and acidosis in hippocampal CA1 neurons. J Physiol. 2015; 593(19): 4373-86. doi: 10.1113/JP270701.

8. Mokhtari T, Akbari M, Malek F, Kashani IR, Rastegar $\mathrm{T}$, Noorbakhsh $\mathrm{F}$, et al. Improvement of memory and learning by intracerebroventricular microinjection of T3 in rat model of ischemic brain stroke mediated by upregulation of BDNF and GDNF in CA1 hippocampal region. Daru. 2017; 25(1): 4. doi: 10.1186/s40199-0170169-x.

9. Ni J, Ohta H, Matsumoto K, Watanabe H. Progressive cognitive impairment following chronic cerebral hypoperfusion induced by permanent occlusion of bilateral carotid arteries in rats. Brain Res. 1994; 653(12): 231-6.

10. Li W, Huang R, Shetty RA, Thangthaeng N, Liu R, Chen $\mathrm{Z}$, et al. Transient focal cerebral ischemia induces long-term cognitive function deficit in an experimental ischemic stroke model. Neurobiol Dis. 2013; 59: 18-25. doi: 10.1016/j.nbd.2013.06.014.

11. Dong W, Yan B, Johnson BP, Millist L, Davis S, Fielding $\mathrm{J}$, et al. Ischaemic stroke: the ocular motor system as a sensitive marker for motor and cognitive recovery. J Neurol Neurosurg Psychiatry. 2013;84(3):337-41. doi: 10.1136/jnnp-2012-303926.

12. Cheatwood JL, Emerick AJ, Kartje GL. Neuronal plasticity and functional recovery after ischemic stroke. Top Stroke Rehabil. 2008; 15(1):42-50. doi: 10.1310/tsr1501-42.

13. Stout JM, Knapp AN, Banz WJ, Wallace DG, Cheatwood JL. Subcutaneous daidzein administration enhances recovery of skilled ladder rung walking performance following stroke in rats. Behav Brain Res. 2013; 256: 428-31. doi: 10.1016/j.bbr.2013.08.027.

14. van Praag H, Shubert T, Zhao C, Gage FH. Exercise enhances learning and hippocampal neurogenesis in aged mice. J Neurosci. 2005; 25(38): 8680-5.

15. Kim J, Park JH, Yim J. Effects of respiratory muscle and endurance training using an individualized training device on the pulmonary function and exercise capacity in stroke patients. Med Sci Monit. 2014; 20: 2543-9. DOI:10.1523/JNEUROSCI.1731-05.2005.

16. Chen CC, Chang MW, Chang CP, Chan SC, Chang WY, Yang CL, et al. A forced running wheel system with a microcontroller that provides high-intensity exercise training in an animal ischemic stroke model. Braz J Med Biol Res. 2014; 47(10): 858-68.

17. Schmidt A, Wellmann J, Schilling M, Strecker JK, Sommer C, Schabitz WR, et al. Meta-analysis of the efficacy of different training strategies in animal models of ischemic stroke. Stroke. 2014; 45(1): 239-47.

18. Kim G, Kim E. Effects of treadmill training on limb motor function and acetylcholinesterase activity in rats with stroke. J Phys Ther Sci. 2013; 25(10): 1227-30. doi: 10.1589/jpts.25.1227.

19. Macko RF, Ivey FM, Forrester LW, Hanley D, Sorkin JD, Katzel LI, et al. Treadmill exercise rehabilitation improves ambulatory function and cardiovascular fitness in patients with chronic stroke: a randomized, controlled trial. Stroke. 2005; 36(10): 220611.
21. Ammann BC, Knols RH, Baschung P, de Bie RA, de Bruin ED. Application of principles of exercise training in sub-acute and chronic stroke survivors: a systematic review. BMC Neurol. 2014;14:167. doi: 10.1186/s12883014-0167-2.

20. Mehrholz J, Pohl M, Elsner B. Treadmill training and body weight support for walking after stroke. Cochrane Database Syst Rev. 2014(1): Cd002840. DOI: 10.1002/14651858.CD002840.pub.

22. Moseley AM, Stark A, Cameron ID, Pollock A. Treadmill training and body weight support for walking after stroke. Cochrane Database Syst Rev. 2003(3): Cd002840.

23. Yang YR, Wang RY, Wang PS. Early and late treadmill training after focal brain ischemia in rats. Neurosci Lett. 2003; 339(2): 91-4.

24. McEwen BS. Stress and hippocampal plasticity. Annu Rev Neurosci. 1999; 22: 105-22.

25. Ahn JH, Park JH, Park J, Shin MC, Cho JH, Kim IH, et al. Long-term treadmill exercise improves memory impairment through restoration of decreased synaptic adhesion molecule 1/2/3 induced by transient cerebral ischemia in the aged gerbil hippocampus. Exp Gerontol. 2018;103:124-31. doi: 10.1016/j.exger.2018.01.015.

26. Cechetti F, Worm PV, Elsner VR, Bertoldi K, Sanches E, Ben J, et al. Forced treadmill exercise prevents oxidative stress and memory deficits following chronic cerebral hypoperfusion in the rat. Neurobiol Learn Mem. 2012; 97(1): 90-6. doi: 10.1016/j.nlm.2011.09.008.

27. Matsuda F, Sakakima H, Yoshida Y. The effects of early exercise on brain damage and recovery after focal cerebral infarction in rats. Acta Physiol (Oxf). 2011; 201(2): 275-87.

28. Shaughnessy M, Michael K, Resnick B. Impact of treadmill exercise on efficacy expectations, physical activity, and stroke recovery. J Neurosci Nurs. 2012; 44(1): 27-35

29. Erfani S, Khaksari M, Oryan S, Shamsaei N, Aboutaleb N, Nikbakht F. Nampt/PBEF/visfatin exerts neuroprotective effects against ischemia/reperfusion injury via modulation of $\mathrm{Bax} / \mathrm{Bcl}-2$ ratio and prevention of caspase-3 activation. J Mol Neurosci. 2015; 56(1): $237-43$.

30. Bedford TG, Tipton CM, Wilson NC, Oppliger RA, Gisolfi CV. Maximum oxygen consumption of rats and its changes with various experimental procedures. $\mathrm{J}$ Appl Physiol Respir Environ Exerc Physiol. 1979;47(6):127883. DOI:10.1152/jappl.1979.47.6.1278.

31. Metz GA, Whishaw IQ. The ladder rung walking task: a scoring system and its practical application. J Vis Exp. 2009; (28). pii: 1204. doi: 10.3791/1204.

32. Metz GA, Whishaw IQ. Cortical and subcortical lesions impair skilled walking in the ladder rung walking test: a new task to evaluate fore- and hindlimb stepping, placing, and co-ordination. J Neurosci Methods. 2002; 115(2): 169-79.

33. Cheatwood JL, Corwin JV, Reep RL. Overlap and interdigitation of cortical and thalamic afferents to dorsocentral striatum in the rat. Brain Res. 2005;1036(12):90-100. 
34. Cheatwood JL, Burnet D, Butteiger DN, Banz WJ. Soy protein diet increases skilled forelimb reaching function after stroke in rats. Behav Brain Res. 2011; 216(2): 681-4.

35. Kirino T, Tamura A, Sano K. Selective vulnerability of the hippocampus to ischemia--reversible and irreversible types of ischemic cell damage. Prog Brain Res. 1985; 63: 39-58.

36. Shamsaei N, Khaksari M, Erfani S, Rajabi H, Aboutaleb N. Exercise preconditioning exhibits neuroprotective effects on hippocampal CAl neuronal damage after cerebral ischemia. Neural Regen Res. 2015; 10(8): 1245-50. doi: 10.4103/1673-5374.162756.

37. Aboutaleb N, Shamsaei N, Rajabi H, Khaksari M, Erfani S, Nikbakht F, et al. Protection of Hippocampal CA1 Neurons Against Ischemia/Reperfusion Injury by Exercise Preconditioning via Modulation of Bax/Bcl-2 Ratio and Prevention of Caspase-3 Activation. Basic Clin Neurosci. 2016; 7(1): 21-9.

38. Sim YJ, Kim H, Kim JY, Yoon SJ, Kim SS, Chang $\mathrm{HK}$, et al. Long-term treadmill exercise overcomes ischemia-induced apoptotic neuronal cell death in gerbils. Physiol Behav. 2005; 84(5): 733-8.

39. Ploughman M, Attwood Z, White N, Dore JJ, Corbett D. Endurance exercise facilitates relearning of forelimb motor skill after focal ischemia. Eur J Neurosci. 2007; 25(11): 3453-60.

40. Shamsaei N, Erfani S, Fereidoni M, Shahbazi A. Neuroprotective Effects of Exercise on Brain Edema and Neurological Movement Disorders Following the Cerebral Ischemia and Reperfusion in Rats. Basic Clin Neurosci. 2017; 8(1): 77-84.
41. Ding Y, Li J, Luan X, Ding YH, Lai Q, Rafols JA, et al. Exercise pre-conditioning reduces brain damage in ischemic rats that may be associated with regional angiogenesis and cellular overexpression of neurotrophin. Neuroscience. 2004; 124(3): 583-91. DOI:10.1016/j.neuroscience.2003.12.029.

42. Lovatel GA, Bertoldi K, Elsnerb VR, Piazza FV, Basso CG, Moyses Fdos S, et al. Long-term effects of pre and post-ischemic exercise following global cerebral ischemia on astrocyte and microglia functions in hippocampus from Wistar rats. Brain Res. 2014;1587:119-26.

43. Carro E, Trejo JL, Busiguina S, Torres-Aleman I. Circulating insulin-like growth factor I mediates the protective effects of physical exercise against brain insults of different etiology and anatomy. J Neurosci. 2001; 21(15): 5678-84.

44. Cohen-Cory S, Kidane AH, Shirkey NJ, Marshak S. Brain-derived neurotrophic factor and the development of structural neuronal connectivity. Dev Neurobiol. 2010; 70(5): 271-88. 